\title{
Serological evidence of H9N2 avian influenza virus exposure among poultry workers from Fars province of Iran
}

\author{
A. Heidari ${ }^{1,2}$, M. Mancin ${ }^{3}$, H. Nilii, G. H. Pourghanbari ${ }^{4,5}$, K. B. Lankarani ${ }^{6}$, S. Leardini ${ }^{1}$, G. Cattoli ${ }^{1}$, I. Monne ${ }^{1}$ \\ and A. Piccirillo ${ }^{2}$
}

\begin{abstract}
Background: Since the 1990s, influenza A viruses of the H9N2 subtype have been causing infections in the poultry population around the globe. This influenza subtype is widely circulating in poultry and human cases of Al H9N2 have been sporadically reported in countries where this virus is endemic in domestic birds. The wide circulation of H9N2 viruses throughout Europe and Asia along with their ability to cause direct infection in mammals and humans, raises public health concerns. H9N2 Al was reported for the first time in Iran in 1998 and at present it is endemic in poultry. This study was carried out to evaluate the exposure to H9N2 Al viruses among poultry workers from the Fars province.
\end{abstract}

Methods: 100 poultry workers and 100 healthy individuals with no professional exposure to poultry took part in this study. Serum samples were tested for antibodies against two distinct H9N2 avian influenza viruses, which showed different phylogenetic clustering and important molecular differences, such as at the amino acid (aa) position 226 (Q/L) (H3 numbering), using haemagglutination inhibition ( $\mathrm{HI})$ and microneutralization (MN) assays.

Results: Results showed that $17 \%$ of the poultry workers were positive for the A/chicken/Iran/10VIR/854-5/2008 virus in $\mathrm{MN}$ test and $12 \%$ in $\mathrm{HI}$ test using the titer $\geq 40$ as positive cut-off value. Only $2 \%$ of the poultry workers were positive for the A/chicken/Iran/12VIR/9630/1998 virus. Seroprevalence of non exposed individuals for both H9N2 strains was below $3 \%$ by both tests. Statistical analyses models showed that exposure to poultry significantly increases the risk of infection with H9N2 virus.

Conclusions: The results have demonstrated that exposure to avian H9N2 viruses had occurred among poultry workers in the Fars province of Iran. Continuous surveillance programmes should be implemented to monitor the presence of avian influenza infections in humans and to evaluate their potential threat to poultry workers and public health.

Keywords: H9N2, Avian influenza, Iran, Poultry workers, Hemagglutination inhibition (HI), Microneutralization (MN)

\footnotetext{
* Correspondence: Ali.h.biotec@gmail.com

${ }^{1}$ Research and Innovation Department, Istituto Zooprofilattico Sperimentale delle Venezie, OIE/FAO and National Reference Laboratory for Newcastle Disease and Avian Influenza, OIE collaborating Center for Diseases at the Human-Animal Interface, Viale dell'Università 10, Legnaro, PD 35020, Italy ${ }^{2}$ Department of Comparative Biomedicine and Food Science, University of Padua, Legnaro, PD, Italy

Full list of author information is available at the end of the article
} 


\section{Background}

Most emerging diseases are of zoonotic origin, with wild and domestic animals acting as natural reservoirs [1]. Globalization and intensive animal farming have led to an increased spread of zoonotic infections [2]. Influenza type A viruses include several distinct subtypes based on the antigenic properties of the two major surface glycoproteins, the hemagglutinin (HA) and the neuraminidase (NA). To date, 18 subtypes of HA (H1-H18) and 11 subtypes of NA (N1-N11) have been described [3]. A number of influenza A subtypes have successfully crossed the species barrier and have established in the mammals and human population, causing yearly seasonal epidemics or they have sporadically been directly transmitted from poultry to humans causing zoonotic infections $[4,5]$. The influenza A viruses of the H9N2 subtype are classified as low pathogenic avian influenza (LPAI) viruses. They cause infections both in wild birds and in the poultry population worldwide, including several countries in Asia, Europe, North Africa and North America [6, 7]. A significant proportion of recent $\mathrm{H} 9 \mathrm{~N} 2$ avian influenza (AI) isolates contains the L226Q (H3 numbering) amino acid substitution in their hemagglutinins (HAs) showing preferential binding to analogs of receptors with sialic acid linked to galactose by $\alpha 2,6$ linkage (SA $\alpha 2,6 \mathrm{Gal})$, a phenotypic portrait which is characteristic of human influenza viruses. Thus, these AI viruses might possess one of the key elements for infection in humans [8-10]. Indeed, H9N2 viruses were isolated for the first time from humans in Hong Kong in 1999 and further human infections were reported in 2003 $[11,12]$. These studies have shown that avian H9N2 viruses isolated from chickens are closely related to the H9N2 viruses responsible for human infection [13]. One human case of H9N2 AI was reported in Bangladesh [14] and the World Health Organization (WHO) in 2015 has reported new cases in Egypt and Bangladesh $[15,16]$. In 1998, domestic pigs from Hong Kong were confirmed as being infected with H9N2 influenza, and infections have been reported also in recent years in swine along with other mammals $[17,18]$. Furthermore, H9N2 viruses can contribute with gene segments during reassortment events leading to the generation of novel avian influenza virus that can infect humans (e.g. recent Chinese H7N9 and H10N8 viruses) $[19,20]$. Recent transmission studies have demonstrated that some natural isolates of $\mathrm{H} 9 \mathrm{~N} 2 \mathrm{vi}-$ ruses can acquire the ability to transmit efficiently between ferrets via respiratory droplets. In addition, it has been reported that serial passages of an $\mathrm{H} 9 \mathrm{~N} 2$ virus through guinea pigs can result in the introduction of amino acid substitutions, which increases contact transmission efficiency in this mammalian model [21,22].

The wide circulation of H9N2 viruses throughout Eurasia, along with their ability to cause direct infections in mammals and humans, raises public health concerns on their potential role as candidates for the next influenza pandemic [23]. H9N2 human infection is generally asymptomatic or responsible for mild clinical signs. This may explain the scarcity of evidence accounting for the circulation and transmission of this virus subtype [24]. Nonetheless, human sera positive for H9 subtype were identified in China, India, Iran, Thailand, Cambodia, Romania, Egypt and Pakistan [25-34].

In Iran, the H9N2 subtype was identified for the first time in 1998 and is still circulating in the poultry population. In the affected farms the mortality rate ranges between 20 and $60 \%$, although this may also be attributable to co-infections with other pathogens, such as IBV or Mycoplasma gallisepticum [35]. In spite of the implemented national control measures, which include the mass vaccination of poultry, the virus has rapidly spread and can be considered endemic in the Iranian poultry [36].

Exposure to H9N2 AI viruses in Iranian poultry workers was previously revealed by means of $\mathrm{HI}$ test, using serum titre $\geq 20$ as positive cut-off $[28,29]$. In previous reported studies, the H9N2 AI seroprevalence, assessed by means of $\mathrm{HI}$ test, in Iranian poultry workers ranged from 1.6 to $15.7 \%$ (Median 9.5). Amongst the Middle-Eastern and Southern Asia countries, the highest seroprevalence was observed in Pakistan $(47.8 \%$ ) by means of $\mathrm{HI}$ test [34] and $7.5 \%$ by means of $\mathrm{MN}$ test in Egypt [33]. In the present study, two different serological tests were used and compared to screen 200 individuals from the Fars province, Iran to better understand the risk of infection with the H9N2 virus in the poultry sector. The two different diagnostic tests were applied to assess whether (i) the human exposure to this virus subtype can be confirmed and whether (ii) the poultry operators in the Iranian endemic areas (the Fars province, in this study) are at risk of exposure to the H9N2 infection.

\section{Results}

The HA gene phylogenetic analysis of 88 Iranian H9N2 strains collected between 1998-2014 shows that they belong to two different groups of G1 lineage, named sublineage A and sub-lineage B for the purpose of this study (Fig. 1). Sub-lineage A refers to the H9N2 isolates collected between 1998 and 2007, which apparently are no longer circulating among the Iranian poultry, while B includes more recent isolates collected between 2003 and 2014. The amino acid sequence analyses of the Iranian H9N2 viruses showed that sub-lineage A consists of $47 \%(14 / 30)$ of the strains with amino acid Q at position 226 (H3 numbering) and $53 \%(16 / 30)$ with L226 substitution. Interestingly, sub-lineage $\mathrm{B}$ encloses mostly (95\%) (55/58) the strains with amino acid L226. Based on these results, two Iranian H9N2 isolates representatives of sub-lineages A (A/chicken/Iran/12VIR/9630/ 1998) and B (A/chicken/Iran/10VIR/854-5/2008) were 


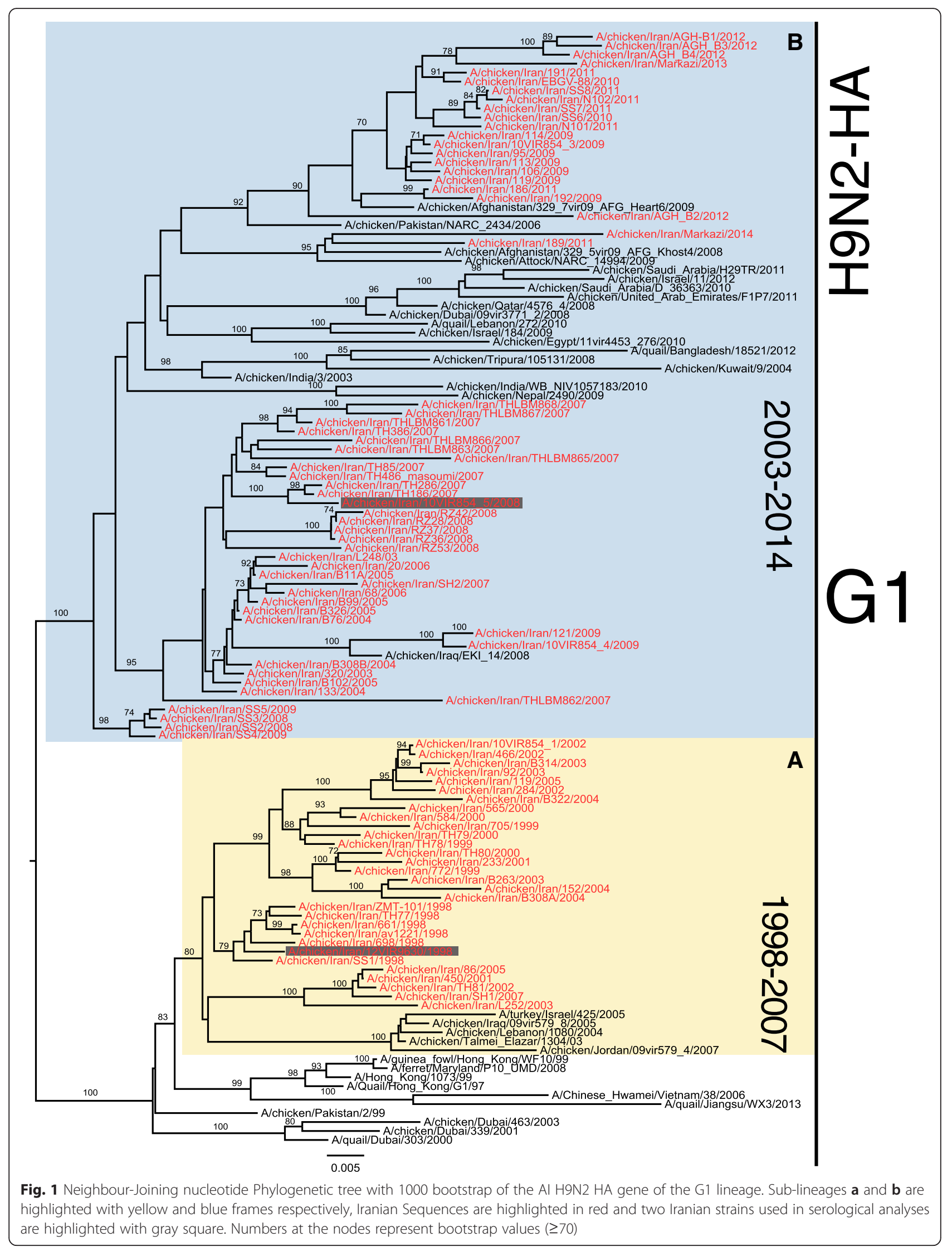


selected as antigens for the serological study (Fig. 1). In particular, A/chicken/Iran/12VIR/9630/1998 was characterized by the amino acid Q226 while the A/chicken/ Iran/10VIR/854-5/2008 virus had amino acid $\mathrm{L}$ at this position. The HA amino acid sequence distance between the two selected strains was $8.1 \%$.

The percentage of seropositive individuals against different influenza viruses obtained with the $\mathrm{HI}$ and $\mathrm{MN}$ tests along with the p-value of the chi-square test related to the association between exposure and response to each virus tested, per method are reported in Table 1. Detailed results of serological investigations obtained for the exposed and unexposed groups against different influenza viruses are described in the supplementary material (Additional file 1: Table S2). Serological results showed that the prevalence of antibodies against A/ chicken/Iran/12VIR/9630/1998 H9N2 (Q 226) was of $2 \%$ in the exposed group by the HI and MN tests, while no positive results were identified in the unexposed group.

An association was observed between professional exposure to poultry species and the presence of antibodies to the A/chicken/Iran/10VIR/854-5/2008 H9N2 (L 226) virus, as revealed by the $\mathrm{HI}$ and MN test $(p<0.05)$. The percentage of positivity was of $12 \%$ for the exposed group and $2 \%$ for the unexposed group in the HI test, while it respectively amounted to $17 \%$ and $3 \%$ for the exposed and unexposed groups in the MN test. Antibody prevalence to H1N1pdm 2009 was of $28 \%$ in the exposed versus $53 \%$ in the unexposed groups by the HI test, and $25 \%$ versus $33 \%$, respectively, by the MN test. For H3N2, the prevalence was $36 \%$ in the exposed group compared to $44 \%$ in the unexposed group with the HI test, while it was $28 \%$ and $24 \%$ in the exposed and unexposed groups with the MN test. The titer distribution percentage against different viruses in different tests (Fig. 2) showed that with the increase of the titre range from $\geq 40$ to $\geq 80$ and from $\geq 80$ to $\geq 160$, the percentage of antibody positivity drastically decreased. Cross MN and HI tests on homologues and different chicken H9N2 hyper immune sera used as positive controls showed the absence of cross reactivity with H1N1pdm 2009 and H3N2 seasonal viruses; the same results were observable in human immune sera for H1N1pdm 2009 and H3N2, which showed the absence of a cross reactivity with the two tested H9N2 viruses.

The probability to be positive against A/chicken/Iran/ 10VIR/854-5/2008 H9N2, H3N2 and H1N1pdm 2009 viruses in different tests was calculated. The generalized linear model for binary responses applied on the H9N2 viruses indicated that the association between professional exposure or absence of professional exposure and H9 infection was significant $(p=0.0018)$. In particular, the exposed and unexposed groups showed a significantly different positivity both in the HI test $(9 \%$ vs. $1 \%$ ) and in the MN test (13\% vs. $2 \%$ ). For the H3N2 virus, the professional exposure was not significantly associated to the presence of antibodies $(p=0.22)$. This means that in both groups the probability of testing positive is almost similar. Differently, the unexposed group showed a significantly higher number of individuals $(p=0.001)$ seropositive to H1N1pdm 2009. If we consider that the H1N1pdm 2009 subtype does not circulate in avian species, it can be assumed that the serological data obtained for this subtype do not depend on the exposure to poultry species; other factors may have been at the origin of the distinct immunoreactivity observed against the H1N1pdm 2009 subtype in the two groups under study.

\section{Discussion and Conclusion}

Results demonstrated that exposure to avian H9N2 viruses had occurred in humans in Iran (Fars province). In particular, the analysis showed a significantly higher prevalence of neutralizing antibodies against the $\mathrm{A} /$ chicken/Iran/10VIR/854-5 H9N2 virus in poultry workers than in the professionally unexposed group. These results are in accordance with a previously reported study from Iran by Alizadeh et al. [28] confirming that poultry workers are at risk of infection from zoonotic avian influenza virus. For the first time in this study, two distinct H9N2 LPAI viruses were used as antigens for serological investigations in humans. Interestingly, neutralizing activity against just one of these two antigens was revealed in several sera, which has resulted in significant different

Table 1 Positive titer percentages and p-value of the chi square test related to the association between exposure and response to each virus tested, per method

\begin{tabular}{|c|c|c|c|c|c|c|}
\hline \multirow{4}{*}{ Virus } & \multicolumn{6}{|c|}{ Triple test average (100 sample subjects) } \\
\hline & \multicolumn{3}{|c|}{$\mathrm{HI}$} & \multicolumn{3}{|c|}{$\mathrm{MN}$} \\
\hline & $\%$ Positive & $\%$ Positive & $p-$ & $\%$ Positive & $\%$ Positive & $\overline{p-}$ \\
\hline & Exposed group & Unexposed group & & Exposed group & Unexposed group & \\
\hline H9N2 A/chicken/Iran/12VIR/9630/1998 & 2 & 0 & 0.01 & 2 & 0 & 0.01 \\
\hline H9N2 A/chicken/Iran/10VIR/854-5/2008 & 12 & 2 & 0.005 & 17 & 3 & 0.001 \\
\hline H1N1pdm 2009 A/California/4/2009 & 28 & 53 & 0.0003 & 25 & 33 & 0.02 \\
\hline H3N2 A/Minnesota/11/2010 & 36 & 44 & 0.02 & 28 & 24 & 0.05 \\
\hline
\end{tabular}




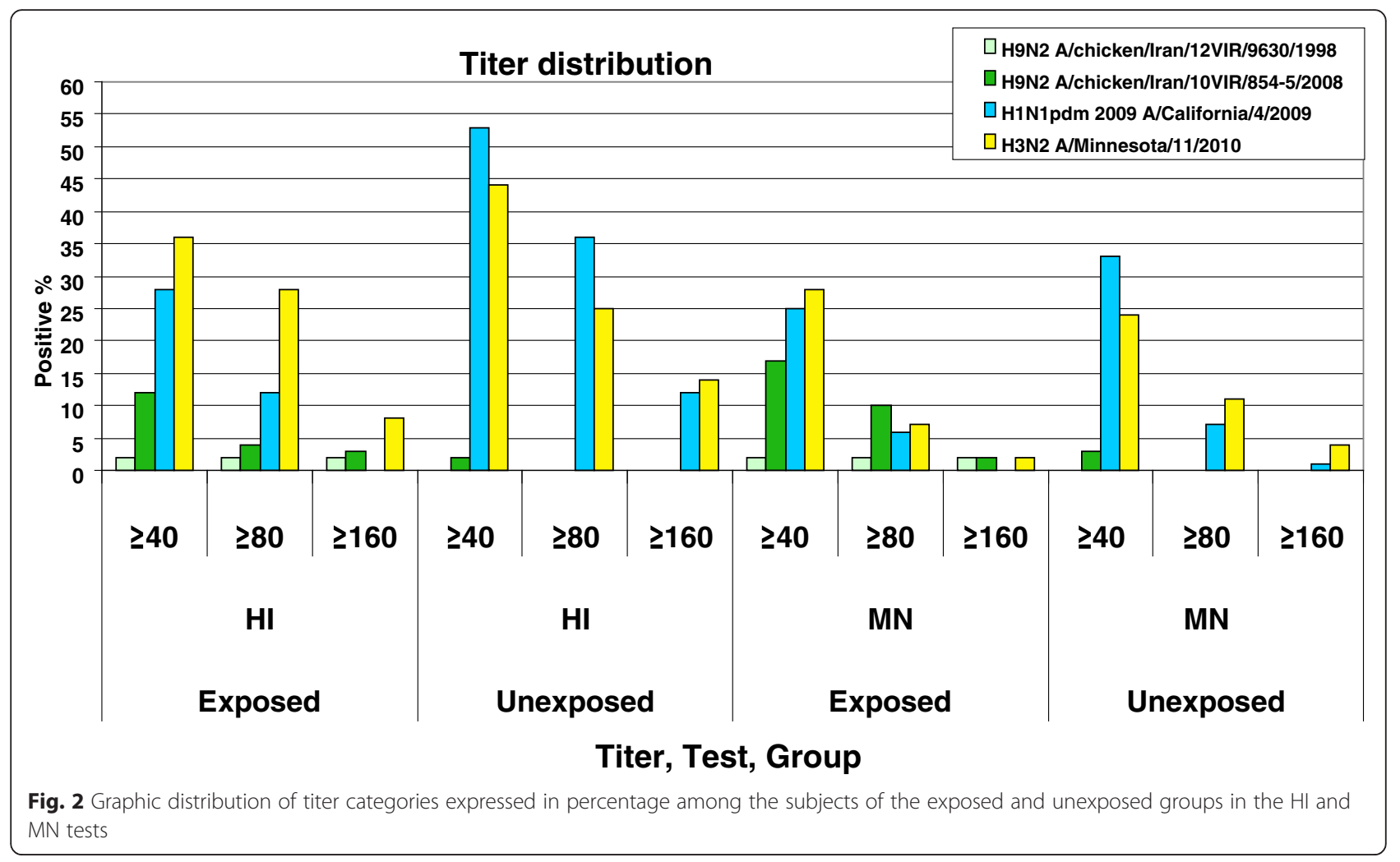

prevalence. This is consistent with the amino acid diversity of the two H9N2 antigens used in this study. In fact, the HA amino acid sequences of A/chicken/Iran/12VIR/ 9630/1998 (Q-226) and A/chicken/Iran/10VIR/854-5/ 2008 (L-226) differed for 43 amino acids, seven of which were located in antigenic sites (S158N, S160L, S175D, E190A, S193N, N208D, Q226L (H3 numbering)) previously reported by other groups [37-40]. These amino acid substitutions may account for the different serological reactivity against these antigens. However, the difference in prevalence observed in this study between two tested H9N2 viruses might have different explanations.

The receptor binding properties of A/chicken/Iran/ 12VIR/9630/1998 H9N2 (Q-226)-like viruses affect their ability to infect humans. As a consequence, the infections of this virus in the exposed population are limited. On the contrary, the A/chicken/Iran/10VIR/854-5 H9N2 (L-226) - like viruses, have increased ability to infect humans resulting in higher prevalence in the exposed population. However, it should be considered that the molecular analysis of Iranian H9N2 viruses demonstrated that those harbouring the Q-226 mutations apparently are no longer in circulation. Furthermore, one previous study investigating the serologic response in humans exposed to avian viruses concluded that the incidence of seroconversion is low and that the antibody response after mild/asymptomatic infections is short-lived [41]. Therefore, the reduction of the circulation of Q-226 viruses in the poultry in recent times and/or the low antibody response after infection might be responsible for the decreased prevalence of antibodies against these $\mathrm{AI}$ viruses.

Consistently with the results discussed so far, the unexposed group counting 100 healthy subjects showed a very low percentage of positivity for $\mathrm{H} 9 \mathrm{~N} 2$ by the $\mathrm{HI}$ and $\mathrm{MN}$ tests, while the distribution of positive titres against H1N1pdm 2009 and seasonal H3N2 influenzas were similar in the exposed and in the unexposed groups.

According to Stephenson et al. [42] the cross reacting antibodies against $\mathrm{H} 2$ might explain the antibody reactivity against avian $\mathrm{H} 9 \mathrm{~N} 2$, especially among people born before 1968. Although we did not test the sera for this antigen, to evaluate this hypothesis, the age of each individual who had tested $\mathrm{H} 9$ positive was verified. Only one sample was from a person born before 1968, while all the others were collected from younger subjects with an age between $22-46$ years, who could not be positive for $\mathrm{H} 2 \mathrm{~N} 2$.

The comparison between the serological results obtained using the $\mathrm{HI}$ and $\mathrm{MN}$ tests against H9N2 showed that the MN test detected more positive samples within the same group, however, the triple test results proved that the HI titer was reasonably more consistent than the MN test. In addition, different researches have reported that intra-laboratory reproducibility by $\mathrm{MN}$ is lower than the one resulting from the HI test [43], a fact 
that may explain the moderate discrepancy observed between the two serological assays applied for the detection of antibodies against H1N1pdm 2009 and H3N2 seasonal influenza. Both in the $\mathrm{HI}$ and $\mathrm{MN}$ tests, the percentage of positivity for $\mathrm{H} 9 \mathrm{~N} 2$ decreased with the increase of the titre range; the obtained results were justified on the grounds that humans have a poor immune response to infections with avian influenza viruses. For instance, studies have shown that the individuals with mild or asymptotic infections had a lower antibody titer compared to individuals who had seriously developed the illness [44]. H9N2 AI viruses have some of the specific molecular markers for the infection of mammals; however, they are still unable to completely adapt to mammals and to cause serious disease in humans, which may explain the low titers observed. As well, the time elapsed between the infection and sampling dates can also account for the decrease of the antibody titer.

In conclusion, this study has highlighted the potential of avian to human transmission of H9N2 AIVs, and indicated that poultry workers are at risk of infection. Avian transmission of H9N2 viruses in humans can increase the probability of human adaption, while genetic reassortment with other human seasonal viruses are means of generating an influenza virus with epidemic or pandemic potential. Hence, integrated medical-veterinary surveillance and research activities are essential in order to identify the emergence of new influenza viruses, assess the clinical significance of seropositivity and understand more on the mechanisms that favour the virus to cross the species barrier. In the poultry sector, surveillance and control programmes should be implemented to reduce the prevalence of H9N2 AIV in poultry population and minimize the risk of exposure in poultry operators.

\section{Methods}

\section{Study population and sample collection}

The analyses were conducted on the blood sera of 100 workers regularly exposed to poultry (exposed group) and of 100 individuals with no professional exposure to poultry (unexposed group). The individuals, belonging to the exposed group, were recruited among the operators of the poultry industry and of the University Poultry Veterinary Hospital, none of whom had been vaccinated against flu. In particular, blood samples were collected between September - December 2012 from 70 slaughterhouse workers, 30 poultry house workers and from 10 operators of the University Poultry Veterinary Hospital, all resident in the Fars province (southern Iran). In January 2013, 100 sera were also collected from subjects from the same province not professionally exposed to poultry. $98 \%$ of the individuals included in the study were males, whose mean age among the poultry workers was of 32 years (ranging between 18-62). The mean age in the professionally unexposed group was of 41 years (range between 18-67). After blood collection the serum was separated, stored at $-20{ }^{\circ} \mathrm{C}$ and subsequently sent to IZSVe for the serological analyses.

\section{Ethics statement}

The use of serum samples for research purposes was approved by the Veterinary University of Shiraz in compliance with the Iranian ethical principles and institutions and according to the principles expressed in the World Medical Association Declaration of Helsinki. Informed consent was obtained from all participating individuals.

\section{Selection of antigens and sera}

To select representative $\mathrm{H} 9$ antigens to be used in the serological investigations, the HA gene nucleotide and amino acid sequences of five Iranian H9N2 AIV isolates available at IZSVe repository were analysed and compared with the Iranian sequences available in the GenBank. Subsequently, a nucleotide sequence dataset of 88 Iranian strains along with representative strains of G1 lineage were aligned and phylogenetically analysed constructing a Neighbour-Joining phylogenetic tree by the MEGA 5 (http://www.megasoftware.net) program (see results). In addition, sera of all individuals were tested for the presence of antibodies to seasonal A/Minnesota/ 11/2010 H3N2 and A/California/4/2009 H1N1pdm 2009 viruses. Positive control sera containing antibodies directed against the selected $\mathrm{H} 9 \mathrm{~N} 2$ antigens were produced in SPF chickens. In addition, a panel of different H9N2, H1N1, H3N2 chicken sera and an H1N1, H3N2 positive human sera were used as controls in the serological assays.

\section{Serological methods}

\section{Hemagglutinin inhibition (HI) test}

The HI assay was applied according to the World Health Organization (WHO) and World Organisation for Animal Health (OIE) manual [45, 46]. Briefly, $0.5 \%$ (vol/vol) chicken red blood cell (RBC) solution was prepared by washing with Phosphate buffered saline (PBS) containing $0.5 \%$ Bovine serum albumin (BSA) (Sigma). To remove non specific serum inhibitors, the human serum samples were treated with $\mathrm{RDE}$ (receptor destroying enzyme) (Sigma-Aldrich) that was reconstituted with $5 \mathrm{ml}$ sterile distilled water. $50 \mu \mathrm{l}$ of serum was added to $200 \mu \mathrm{l}$ of RDE diluted to $100 \mathrm{ml}$ with calcium saline, PH 7.2 and incubated overnight at $37^{\circ} \mathrm{C}$. Then 5 vol of $1.5 \%$ sodium citrate were added then heated at $56{ }^{\circ} \mathrm{C}$ for $30 \mathrm{~min}$ to inactivate remaining $\mathrm{RDE}$. The treated sera were tested by haemagglutination assay to verify the presence of non-specific agglutination. After that the treated serum $(50 \mu \mathrm{l}$ of each one) was diluted in two-fold serial dilutions (1:10) with 
$25 \mu \mathrm{l} \mathrm{PBS}$ in 96-well V-bottom microtiter plates. Subsequently, $25 \mu \mathrm{l}$ of virus antigens containing $4 \mathrm{HA}$ units were added to the wells and incubated at room temperature (RT) for 30-45 min. $50 \mu \mathrm{l}$ of $0.5 \%$ chicken RBCs were then added and the plate was incubated further for $45 \mathrm{~min}$ at RT before recording the agglutination titers. The HI test results were expressed as the reciprocal of the last dilution of the sample that completely inhibited haemagglutination. In all the assays control positive serum samples were included, and all assays were tested in triplicate.

\section{Microneutralization (MN) test}

The WHO MN test protocol was applied [47]. The human serum samples were inactivated by heating at $56{ }^{\circ} \mathrm{C}$ for 30 min $\mathrm{H} 9 \mathrm{~N} 2, \mathrm{H} 3 \mathrm{~N} 2$ and H1N1pdm virus stocks used in our analyses were titrated in the presence of TPCK-trypsin $(2 \mu \mathrm{g} / \mathrm{ml})$ (Sigma-Aldrich) for determination of tissue culture infectious dose (TCID50). $10 \mu \mathrm{l}$ of treated sera were added to 96 well cell culture plates (Costar) and 2-fold serial dilutions were performed. Inoculum was prepared in virus diluent with the addition of TPCK-trypsin $(2 \mu \mathrm{g} / \mathrm{ml})$ so that $50 \mu \mathrm{l}$ contained 100 TCID50 of the respective virus. Fifty microliters of virus inoculum was added to the wells, the virus serum mixture was subsequently incubated for $1 \mathrm{hr}$ at $37{ }^{\circ} \mathrm{C}, 5 \%$ $\mathrm{CO} 2$. A back-titration of the virus inoculum was performed in each assay using 2 fold serial dilutions. $100 \mu \mathrm{l}$ MDCK cells $(1.5 \times 104$ cells /well $)$ were then added to each well and the plate was incubated overnight at $37^{\circ} \mathrm{C}$, $5 \%$ CO2 (18-20 hrs). The plate was then fixed with $100 \mu \mathrm{l} /$ well of cold fixative (80 \% Acetone in PBS) for $10 \mathrm{~min}$. The virus was detected with an anti-Influenza A, Nucleoprotein monoclonal antibody (Merck Millipore) and Peroxidase conjugated-goat anti-mouse IgG ( $\gamma$ ) (KPL) as secondary antibody using ELISA. All serum samples and controls were tested in triplicate.

\section{Criteria for seropositivity}

The WHO guidelines for vaccine evaluation suggest that a neutralizing antibody titre $\geq 40$ indicate higher than $50 \%$ protection against influenza A virus infection or disease. Based on this consideration, an individual with an antibody titer $\geq 40$ was considered positive for different serotype in $\mathrm{MN}$ and $\mathrm{HI}$ tests [41].

\section{Statistical Analyses}

The Geometric Mean titers (GMTs) of the triple test per method (HI and MN) was calculated for each subject checked for the virus of interest. A binary variable was created to identify the positive/negative sample. An average titre lower than 40 identified negative samples, whereas an average titre higher than 40 identified positive samples. The Chi square test was used to verify the possible association between positivity and exposure, for each method and virus. The GLM (Generalized linear model) for binary responses was used to estimate the probability to have a positive reaction for each tested virus, considering simultaneously the methods ( $\mathrm{HI}$ and $\mathrm{MN}$ ), the groups (exposed and unexposed) and their interaction as variables. The Maximum Likelihood method was used to estimate the parameters of the model. The Type III F-tests were applied to evaluate the overall effect of specified variables in the model. $P$-values lower than 0.10 were considered as significant [48]. SAS 9.3 software was used to fit the statistical analysis.

\section{Additional file}

Additional file 1: Table S2. Results of serological investigations obtained for the different categories of exposed and unexposed groups against different influenza viruses. (DOC $110 \mathrm{~kb}$ )

\begin{abstract}
Abbreviations
aa: amino acid; Al: Avian Influenza; GMTs: geometic mean titers;

$\mathrm{HA}$ : hemagglutinin; HI: hemagglutinin inhibition; MN: microneutralization assay; MDCK: Madin-Darby canine kidney; OIE: Organisation for Animal Health; pdm: pandemic; WHO: World Health Organization.
\end{abstract}

\section{Competing interests}

The authors declare that they have no competing interests.

\section{Authors' contributions}

HA furnished intellectual contributions, was involved in sample testing, date analysis and drafted the manuscript. NH, LKB and PGH were involved in sample and data collection. MM provided the statistical analyses support. MI and CG supervised the laboratory analysis and the results interpretation. LS provided the technical support and PA contributed to the results interpretation. All authors read and approved the final manuscript.

\section{Acknowledgements \\ This project was financially supported by the NoFlu project, Fondazione Cariplo Vaccine Program (grant number 2009-3594). The authors would like to acknowledge Dr. Angela Trocino (Department of Comparative Biomedicine and Food Science, University of Padua, Italy) for her contribution in the statistical analysis, Daniele Facco, Lorenza Boscolo and Silvia Maniero (DSBIO, IZSVe, Padova, Italy) for technical support and Francesca Ellero (DSBIO, IZSVe, Padova, Italy) for providing language help. In addition, we gratefully acknowledge the contributing authors and the originating and submitting laboratories for the sequences from the Global Initiative on Sharing All Influenza Data (GISAID) EpiFlu database. This study was conducted in the framework of the Doctoral school in Veterinary Science at the University of Padua (Alireza Heidari).}

\section{Author details}

${ }^{1}$ Research and Innovation Department, Istituto Zooprofilattico Sperimentale delle Venezie, OIE/FAO and National Reference Laboratory for Newcastle Disease and Avian Influenza, OIE collaborating Center for Diseases at the Human-Animal Interface, Viale dell'Università 10, Legnaro, PD 35020, Italy. ${ }^{2}$ Department of Comparative Biomedicine and Food Science, University of Padua, Legnaro, PD, Italy. ${ }^{3}$ Food safety department, Istituto Zooprofilattico Sperimentale delle Venezie (IZSVe), Viale dell'Università 10, Legnaro, PD 35020, Italy. ${ }^{4}$ Avian Diseases Research Center, School of Veterinary Medicine, Shiraz University, Shiraz, Iran. ${ }^{5}$ School of Veterinary Medicine, Ardakan University, Yazd, Iran. ${ }^{6}$ Health Policy Research Center of Shiraz University of Medical Science, Shiraz, Iran. 


\section{References}

1. Kruse H, Kirkemo AM, Handeland K. Wildlife as source of zoonotic infections. Emerg Infect Dis. 2004;10(12):2067-72.

2. Cutler SJ, Fooks AR, van der Poel WH. Public health threat of new reemerging, and neglected zoonoses in the industrialized world. Emerg Infect Dis. 2010;16(1):1-7.

3. Tong S, Zhu X, Li Y, Shi M, Zhang J, Bourgeois M, et al. New world bats harbor diverse influenza A viruses. PLoS Pathog. 2013;9(10):e1003657.

4. Riedel S. Crossing the species barrier: the threat of an avian influenza pandemic. Proc (Bayl Univ Med Cent). 2006;19(1):16-20.

5. Katz JM, Veguilla V, Belser JA, Maines TR, Van Hoeven N, Pappas C, et al. The public health impact of avian influenza viruses. Poult Sci. 2009;88(4):872-9.

6. Alexander DJ. Report on avian influenza in the Eastern Hemisphere during 1997-2002. Avian Dis. 2003;47(3 Suppl):792-7.

7. Brown IH, Banks J, Manvell RJ, Essen SC, Shell W, Slomka M, et al. Recent epidemiology and ecology of influenza A viruses in avian species in Europe and the Middle East. Dev Biol (Basel). 2006;124:45-50.

8. Lin YP, Shaw M, Gregory V, Cameron K, Lim W, Klimov A, et al. Avian-tohuman transmission of H9N2 subtype influenza A viruses: relationship between $\mathrm{H} 9 \mathrm{~N} 2$ and H5N1 human isolates. Proc Natl Acad Sci U S A. 2000:97(17):9654-8.

9. Ge FF, Zhou JP, Liu J, Wang J, Zhang WY, Sheng LP, et al. Genetic evolution of $\mathrm{H} 9$ subtype influenza viruses from live poultry markets in Shanghai, China. J Clin Microbiol. 2009;47(10):3294-300.

10. Wan H, Perez DR. Amino acid 226 in the hemagglutinin of H9N2 influenza viruses determines cell tropism and replication in human airway epithelial cells. J Virol. 2007:81(10):5181-91.

11. Saito T, Lim W, Suzuki T, Suzuki Y, Kida H, Nishimura SI, et al. Characterization of a human H9N2 influenza virus isolated in Hong Kong. Vaccine. 2001;20(1-2):125-33.

12. Butt KM, Smith GJ, Chen H, Zhang $L$, Leung YH, Xu KM, et al. Human infection with an avian H9N2 influenza A virus in Hong Kong in 2003. J Clin Microbiol. 2005;43(11):5760-7

13. Cameron KR, Gregory V, Banks J, Brown IH, Alexander DJ, Hay AJ, et al, H9N2 subtype influenza A viruses in poultry in pakistan are closely related to the H9N2 viruses responsible for human infection in Hong Kong. Virology. 2000;278(1):36-41

14. Shanmuganatham K, Feeroz MM, Jones-Engel L, Smith GJ, Fourment M, Walker D, et al. Antigenic and molecular characterization of avian influenza A(H9N2) viruses, Bangladesh. Emerg Infect Dis. 2013;19(9):1393-1402.

15. World health organization (WHO) Influenza at the human-animal interface, Summary and assessment as of 23 June2015. http://www.who.int/influenza/ human_animal_interface/Influenza_Summary_IRA_HA_interface_23_June_ 2015.pdf?ua=1

16. World health organization (WHO) Influenza at the human-animal interface, Summary and assessment as of 4 September 2015. http://www.who.int/ influenza/human_animal_interface/Influenza_Summary_IRA_HA_interface_ 04_September_2015.pdf

17. Peiris JS, Guan Y, Markwell D, Ghose P, Webster RG, Shortridge KF. Cocirculation of avian H9N2 and contemporary "human" H3N2 influenza A viruses in pigs in southeastern China: potential for genetic reassortment? J Virol. 2001;75(20):9679-86.

18. Peng L, Chen C, Kai-yi H, Feng-xia Z, Yan-li Z, Zong-shuai L, et al. Molecular characterization of H9N2 influenza virus isolated from mink and its pathogenesis in mink. Vet Microbiol. 2015;176(1-2):88-96.

19. Gao R, Cao B, Hu Y, Feng Z, Wang D, Hu W, et al. Human infection with a novel avian-origin influenza A (H7N9) virus. N Engl J Med. 2013;368(20):1888-97.

20. Zhang T, Bi Y, Tian H, Li X, Liu D, Wu Y, et al. Human infection with influenza virus $\mathrm{A}(\mathrm{H} 10 \mathrm{~N} 8)$ from live poultry markets, China, 2014. Emerg Infect Dis. 2014;20(12):2076-9.

21. Li X, Shi J, Guo J, Deng G, Zhang Q, Wang J, et al. Genetics, receptor binding property, and transmissibility in mammals of naturally isolated H9N2 Avian Influenza viruses. PLoS Pathog. 2014;10(11):e1004508.

22. Sang X, Wang A, Ding J, Kong H, Gao X, Li L, et al. Adaptation of H9N2 AIV in guinea pigs enables efficient transmission by direct contact and inefficient transmission by respiratory droplets. Sci Rep. 2015;5:15928.

23. Li KS, Xu KM, Peiris JS, Poon LL, Yu KZ, Yuen KY, et al. Characterization of $\mathrm{H} 9$ subtype influenza viruses from the ducks of southern China: a candidate for the next influenza pandemic in humans? J Virol. 2003;77(12):6988-94
24. Liu Q, Liu DY, Yang ZQ. Characteristics of human infection with avian influenza viruses and development of new antiviral agents. Acta Pharmacol Sin. 2013;34(10):1257-69.

25. Wang Q, Ju L, Liu P, Zhou J, Lv X, Li L, et al. Serological and Virological Surveillance of Avian Influenza A Virus H9N2 Subtype in Humans and Poultry in Shanghai, China, Between 2008 and 2010. Zoonoses Public Health. 2015;62(2):131-40.

26. Pawar SD, Tandale BV, Raut CG, Parkhi SS, Barde TD, Gurav YK, et al. Avian influenza H9N2 seroprevalence among poultry workers in Pune, India, 2010. PLoS One. 2012;7(5):e36374.

27. Hadipour MM, Pazira S. Evaluation of Antibody Titers to H9N2 Influenza Virus in Hospital Staff in Shiraz, Iran. Journal of Animal and Veterinary Advance. 2011:10(7):832-4.

28. Alizadeh E, Kheiri MT, Bashar R, Tabatabaeian M, Hosseini SM. Avian Influenza (H9N2) among poultry workers in Iran. Iranian Journal of Microbiology. 2009;1:3-6.

29. Anvar E, Hosseini SM, Tavasoti Kheiri M, Mazaheri V, Fazaei K, Shabani M, et al. Serological Survey of Avian Influenza (H9N2) Among Different Occupational Groups in Tehran and Qazvin Provinces in IR Iran. Jundishapur J Microbiol. 2013;6(4):e5441.

30. Khuntirat BP, Yoon IK, Blair PJ, Krueger WS, Chittaganpitch M, Putnam SD, et al. Evidence for subclinical avian influenza virus infections among rural Thai villagers. Clin Infect Dis. 2011;53(8):e107-16.

31. Blair PJ, Putnam SD, Krueger WS, Chum C, Wierzba TF, Heil GL, et al. Evidence for avian H9N2 influenza virus infections among rural villagers in Cambodia. J Infect Public Health. 2013;6(2):69-79.

32. Coman A, Maftei DN, Krueger WS, Heil GL, Friary JA, Chereches RM, et al. Serological evidence for avian H9N2 influenza virus infections among Romanian agriculture workers. J Infect Public Health. 2013;6(6):438-47.

33. Gomaa MR, Kayed AS, Elabd MA, Zeid DA, Zaki SA, El Rifay AS, et al. Avian influenza $A(\mathrm{H} 5 \mathrm{~N} 1)$ and $A(\mathrm{H} 9 \mathrm{~N} 2)$ seroprevalence and risk factors for infection among Egyptians: a prospective, controlled seroepidemiological study. J Infect Dis. 2015:211(9):1399-407.

34. Ahad A, Thornton RN, Rabbani M, Yaqub T, Younus M, Muhammad K, et al. Risk factors for $\mathrm{H} 7$ and $\mathrm{H} 9$ infection in commercial poultry farm workers in provinces within Pakistan. Prev Vet Med. 2014;117(3-4):610-4.

35. Nili $H$, Asasi K. Avian influenza (H9N2) outbreak in Iran. Avian Dis. 2003:47(3):828-31.

36. Vasfi Marandi M. Current Situation of Avian Influenza in Iran and around the World. Poultry Industry. 2013 http://en.engormix.com/MA-poultry-industry/ health/articles/current-situation-avian-influenza-t3018/165-p0.htm

37. Kaverin NV, Rudneva IA, Ilyushina NA, Lipatov AS, Krauss S, Webster RG. Structural differences among hemagglutinins of influenza A virus subtypes are reflected in their antigenic architecture: analysis of $\mathrm{H} 9$ escape mutants. J Virol. 2004;78(1):240-9.

38. Zhu $Y$, Yang D, Ren Q, Yang $Y$, Liu $X, X u X$, et al. Identification and characterization of a novel antigenic epitope in the hemagglutinin of the escape mutants of H9N2 avian influenza viruses. Vet Microbiol. 2015;178(1-2):144-9.

39. Okamatsu M, Sakoda Y, Kishida N, Isoda N, Kida H. Antigenic structure of the hemagglutinin of H9N2 influenza viruses. Arch Virol. 2008;153(12):2189-95.

40. Yasugi M, Kubota-Koketsu R, Yamashita A, Kawashita N, Du A, Misaki R, et al. Emerging antigenic variants at the antigenic site $\mathrm{Sb}$ in pandemic A(H1N1)2009 influenza virus in Japan detected by a human monoclonal antibody. PLoS One. 2013;8(10):e77892.

41. Eichelberger M, Golding $H$, Hess M, Weir J, Subbarao $K$, Luke CJ, et al. FDA/NIH/WHO public workshop on immune correlates of protection against influenza $A$ viruses in support of pandemic vaccine development, Bethesda, Maryland, US, December 10-11, 2007. Vaccine. 2008;26(34):4299-303.

42. Stephenson I, Nicholson KG, Glück R, Mischler R, Newman RW, Palache AM, et al. Safety and antigenicity of whole virus and subunit influenza A/Hong Kong/1073/99 (H9N2) vaccine in healthy adults: phase I randomised trial. Lancet. 2003;362(9400):1959-66.

43. Stephenson I, Heath A, Major D, Newman RW, Hoschler K, Junzi W, et al. Reproducibility of serologic assays for influenza virus A (H5N1). Emerg Infect Dis. 2009:15(8):1252-9.

44. Buchy P, Vong S, Chu S, Garcia JM, Hien TT, Hien VM, et al. Kinetics of neutralizing antibodies in patients naturally infected by H5N1 virus. PLoS One. 2010;5(5):e10864 
45. World Health Organization (WHO), Manual on Animal Influenza Diagnosis and Surveillance. http://www.who.int/csr/resources/publications/influenza/ en/whocdscsrncs20025rev.pdf

46. Organisation for Animal Health (OIE), Manual of Diagnostic Tests and Vaccines for Terrestrial Animals 2015 Chapter 2.8.8. http://www.oie.int/ fileadmin/Home/eng/Health_standards/tahm/2.08.08_SWINE_INF.pdf

47. World Health Organization (WHO), protocol of Serological diagnosis of influenza by microneutralization assay. http://www.who.int/influenza/gisrs_ laboratory/2010_12_06_serological_diagnosis_of_influenza_by_ microneutralization_assay.pdf

48. Dohoo IR, Martin W, Stryhn H. Veterinary epidemiologic research. 2nd ed. University of Prince Edward Island, Prince Edward Island, Canada: Atlantic Veterinary College Inc; 2010. p. 865.

Submit your next manuscript to BioMed Central and we will help you at every step:

- We accept pre-submission inquiries

- Our selector tool helps you to find the most relevant journal

- We provide round the clock customer support

- Convenient online submission

- Thorough peer review

- Inclusion in PubMed and all major indexing services

- Maximum visibility for your research

Submit your manuscript at www.biomedcentral.com/submit
Biomed Central 